\title{
Can a technology turn (also) into a symbol? The 3D printers case
}

\author{
Claudio Fassio \\ Lund University, Department of Business Administration, Centre for Innovation Research and \\ Competence in the Learning Economy (CIRCLE), Sölvegatan 16, 22100, Lund, Sweden. \\ Email: claudio.fassio@fek.lu.se
}

Luca Grilli*

Politecnico di Milano, Department of Management, Economics and Industrial Engineering, Via R. Lambruschini 4/b, 20156, Milan, Italy.

Email: luca.grilli@polimi.it

*Corresponding author

\begin{abstract}
3D printing industry has been recently affected by two events: the fact that Open Source (OS) business models are getting momentum, and the widespread diffusion of the Maker Movement. We argue that 3D printers can be conceptualized as innovations which embody both technological and symbolic aspects. If innovations of the first type are solely adopted for their technical utility, innovations who have also symbolic connotation may confer a new social meaning to an item. By analyzing an international sample of 3D printer users, we highlight that adoption of 3D proprietary printers are driven by technologically-rooted considerations, while adherence to the Maker Movement is a key factor behind the adoption of 3D OS printers.
\end{abstract}

Key words: 3D printers, New business models, Social movements JEL codes: O32, L17

Note: This is a pre-print version of the article published in the International Journal of Technology Management. DOI: $\underline{10.1504 / I J T M .2020 .108985}$ 


\section{Introduction}

In the last years the 3D printing industry has experienced a dramatic change driven both by the entry of new producers introducing novel designs and innovative business models and by an expanding demand for 3D printed products and related-services (Piller et al., 2015; Wohlers, 2015; Ford et al., 2016). These dynamics radically challenged the "niche” market for professional 3D printers that existed until a few years ago, potentially expanding it into a larger (mass) market, with a much higher number of potential adopters (De Jong and De Bruijn, 2013; Rayna and Striukova, 2016). The primary reason for this paradigmatic shift is the increasing availability of new low-cost models of 3D printers, which often adopt an Open Source (OS) architecture and target the lower end of the market (Sells et al., 2009; Berman, 2012; Wittbrodt et al., 2013; Kietzmann et al., 2015; West and Kuk, 2016). Established producers were specialized in providing high-quality 3D printing standards and adopted a wholly proprietary system for the development of the technology. On the contrary new comers usually adopt OS licenses for the management of intellectual property rights. Generally, these 3D OS printers are considered to be far more flexible and user-centric (Malone and Lipson, 2007), by allowing the end-users to further develop both the software and the hardware components in order to adapt the 3D printer to the specific customer’s needs (Pearce, 2012; Kyriakou and Nickerson, 2014; West and Kuk, 2016).

The massive entry of new OS producers and the impressive growth and enlargement of the 3D printing market (Wohlers, 2013 and 2015) went in parallel with the birth and development of dedicated interest groups and the flourishing of a new cultural stream grouped under the umbrella term of Maker Movement. This community of interest, formed by 3D printer users and “makers”, was based on combining digital tools and the OS sharing philosophy for creating physical objects. It started in the mid-2000s and further consolidated its role thereafter (see "The Maker Movement Manifesto” by Mark Hatch in 2014). 
The fast and turbulent growth of the 3D printing market has led to an increasing interest towards this specific industry by the economic and management literature. However, while a recent wave of research has investigated the impact of the technology of 3D printers on firms' innovative and organizational strategies (De Jong and De Bruijn, 2013; Mellor et al., 2014; Kietzmann et al., 2015; Rayna and Striukova 2016), as well as the possible applications of 3D printing to new or existing industries (Berman, 2012; Rayna and Striukova, 2016), very little is known about the demand for 3D printing and the specific motivations that drive individuals to use 3D printers. Furthermore, no study has ever investigated the role that a cultural movement linked to communities of users (West and Lakhani, 2008), like the Maker Movement, can play in these adoption dynamics. To our knowledge this paper is the first contribution that aims at filling this gap.

We propose that in order to understand the pattern of adoption of 3D printing and the role of the Maker Movement, it is useful to think to 3D printers as innovations possessing both technological and symbolic features. This paradigmatic categorization was firstly put forward by Hirschman (1982) and largely used by subsequent new product development (NPD) streams of research that investigate the relationship between the symbolic content of innovations and their diffusion patterns (e.g. Verganti, 2008; Christiansen et al., 2010; Dell'Era, 2010). In a nutshell, it is proposed that, while technological product innovations are mainly adopted for their intrinsic technical characteristics, symbolic product innovations are able to convey new social meanings to already existing items. Our main argument, in this work, is that the growing relevance of communities of interest such as the Maker Movement has contributed to increase the symbolic attributes of 3D printers that adopt an OS architecture (3D OS printers), shaping the motivations that drive their adoption among users (see also Dahlander et al., 2008). On the contrary, the more expensive (and often high quality) 3D printers of established producers (proprietary printers) still retain most of the attributes of a technological product innovation.

On the basis of this theoretical framework we hypothesize that, since technological innovations often require specific skills and competence for their usage, the adopters of 3D proprietary printers 
will be relatively more educated and will mainly use 3D printers for work-related reasons. On the contrary, 3D OS printers will be adopted also because users want to be part of specific communities of interest, such as the Maker Movement. Moreover, we propose that starting from 2011, when the Maker Movement literally took off, the symbolic nature of 3D OS printers became even more relevant than before.

We test empirically our hypotheses on a unique dataset containing detailed information about the characteristics of a sample of users of 3D printers and related services. Besides being one of the few datasets specifically directed to users of 3D printers, one great advantage resides in its international nature, with respondents from 39 different countries, allowing us to truly identify the features of the global demand for 3D printers. The empirical analysis tests the different motivations behind the adoption of 3D OS and proprietary printers, confirming our hypotheses concerning the dual (technological and symbolic) nature of 3D printers, as well as the increasing relevance over time of the symbolic component for what concerns OS printers.

Our study contributes to the theoretical and empirical discourse on the diffusion of new technologies in many ways. On the theoretical ground, we demonstrate how the technological and symbolic categorization of an innovation (Hirschman, 1982) should not necessarily come into timesequence or be alternative. On the contrary both may co-exist in the same product category, with firms adopting different architectures, as to the intellectual property regimes schemes (proprietary vs. open source). This way, we also show how the addition of symbolic features enabled by the OS paradigm to a technological innovation like 3D printers may lead to a strong market segmentation: different types of adopters/users select themselves into the innovation's type, characterized by different endowment in terms of technology and symbolism. Moreover, our analysis provides a novel perspective on the literature that analyzes the emergence of a new industry segment out of an existing one. Existing theories, such as the disruptive framework approach (Christensen, 1997), suggest that disruptive innovators emerge and challenge incumbent organizations primarily through the offer of lower-priced products (with fewer technology attributes), with respect to the high-end products of 
established organizations: hence price motivations represent the main reason behind the emergence of new innovators. The present analysis of the 3D printing case suggests that in some contexts this process can be boosted by the attribution of symbolic value to the disruptive technology by communities of users. This perspective is relevant because it offers managers of both established and new companies interesting insights about the function that communities of adopters may play in the dynamics of innovation diffusion, as well as their impact on market performance. Lastly this theoretically-grounded lens of investigation of the recent evolution of the 3D printing industry may also help innovators and stakeholders in spelling out plausible expectations about the future evolution of the industry.

\section{The evolution of the market of 3D printers}

3D printing technology and the 3D printing industry have constantly evolved throughout time to serve different functions and different types of users. Starting from the 80's, and until the early 2010's, 3D printers have been mainly used by companies for the production of prototypes and mockups in the initial phases of product development, before their actual market introduction (Mellor et al., 2014). The advantages of 3D printers for this purpose consist mainly in the possibility to produce several different versions of a single model with little effort, through a very fast and costsaving process (Berman, 2012). For this reason, the main customers for 3D printers producers have originally been the product-development divisions of large companies.

More recently, however, 3D printing has evolved towards new specific uses and new potential customers: on the one hand, firms have started using 3D printers also for the production of finished products in limited series, or for products to be used in marketing tests (Mellor et al., 2014; Berman, 2012). On the other hand, and probably most importantly, a new wave of 3D producers have started to target directly individuals as potential purchasers of their products (Rayna and Striukova, 2016). This originated a brand new market segment, often labeled as the "personal 3D printers" market, 
which indeed represents the most important market twist occurred in 3D printing in recent years (Wohlers, 2012). The possibility to purchase 3D printers for self-employed engineers, designers and small businesses was made available by the increasing number of 3D producers launching in the market models of 3D printers at relatively low prices (thanks also to the expiration of existing patents related with 3D printing technology), clearly targeting the lower end of the market. The boundaries of this market segment still remain quite blurred.

While possible uses of this new wave of 3D printers may embrace different consumers' needs, it is also true that the large number of new $3 \mathrm{D}$ printer producers offering models at limited prices was spurred (and at the same time fuelled) by the birth and growth of specific communities of interest for users of 3D printers. As in many emerging industries, members of these communities of interest would often set up their own companies and became themselves 3D printers producers (Baldwin et al., 2006). ${ }^{1}$ The personal 3D printers that these company produce are usually called “desktop 3D printers”, to put emphasis on their possible usage at home by single individuals.

\subsection{The new wave of Open Source producers and the Maker Movement}

An important feature of these low-cost 3D printers is that they are often based on OS technologies in both software and hardware components. The adoption of an OS architecture allows users to freely access the knowledge used to design and produce 3D printers. The OS concept defines licensing agreements which enable the possibility to view and modify software source codes (Singh et al., 2015). It originated from Operating System software with Linux (Stallman, 1999; for an early history see Lerner and Tirole, 2002), and it rapidly spread over different areas, including browser (e.g. Mozilla), office automation (e.g. Open office), mobile phones (e.g. Android), media players (e.g. VLC Player), Web servers (e.g. Apache), and many others. In the 3D printing domain OS does not only refer to software design but it also embraces hardware components. From these enhanced

\footnotetext{
${ }^{1}$ In fact, companies as Bits From Bytes, Makerbot, Ultimaker and RepRap are user-founded 3D producers that currently hold the largest market shares in this specific market segment.
} 
possibilities to transform and re-assemble all different parts of a 3D printer stem greater chances for interested people to learn (Kostakis et al., 2015) and start collective projects, which increase the sense of belonging to a specific community. In turn, this is likely to have contributed to change the nature of 3D printing from a mere and pure technological innovation into also a symbolic one. The RepRap project, launched in 2005 by Adrian Bowyer, was one of the first example of such model: Bowyer produced a 3D printer in which users could freely access and modify the software and hardware components with the ultimate aim of improving product performance (De Jong and De Bruijn, 2013). This intended process of continuous improvement of a technological system, through the contribution of different individuals, strongly relies on the possibility for developers to share, within the broad community of users, the novel knowledge associated with modifications. The existence of a community of users is an important characteristic of the recent expansion of the market segment for personal 3D OS printers. Since mid-2000s an international community of individuals interested in the adoption and further development of technologies related with the physical (digital-based) production of items started to take shape. This process was triggered and fueled in the mid 2000's by the launch of specific technologically-oriented publications (e.g. "Make Magazine”) related with the so-called Do-It-Yourself (DIY) perspective and by the organization of events and exhibitions dedicated to the 3D printing phenomenon, such as the "Maker Faires". ${ }^{2}$

Both factors contributed to sustain 3D printing, by allowing an increasing number of individuals interested in the fabrication of objects through digital devices to gather together. In turn, meetings and public conventions enhanced the discussion on relevant topics, and in general the possibilities of confrontation with other "makers", as well as the sharing of ideas and information about 3D printing. Since then, the size of this specific community of users has increased exponentially, as well as the number of Maker Faires exhibitions worldwide and the number of their participants, leading to the emergence of what has been labeled as the Maker Movement (Deloitte, 2014).

\footnotetext{
$\overline{2}$ The Make Magazine was launched in 2005, while the first Maker Faire was organized in California in 2006 by the Make Magazine itself.
} 
The Maker Movement opinion group is an open network of individuals who use digital technologies to make physical objects and who share common ethical values (Anderson, 2012). In particular, the emphasis is on the importance of sharing the knowledge acquired through the activities related with the digital fabrication of items and to offer open access to the output of one's own job to the other members of the community. Other relevant factors are the aim to constantly upgrade competences through learning and the importance of participating in events that gather other members of the movement (see “The Maker Movement Manifesto”, 2014). ${ }^{3}$ These principles are not completely new in the Open Source community, since already in the late 90's and early 2000's similar types of ideas had been fostered by works such as the "Manifesto for Agile Software Development “ (2001) or "the Cathedral and the Bazaar" (Raymond, 1999). However, the Maker Movement community added to such existing ethics of the Open Source community a specific twist towards the Do It Yourself mindset and about the interaction between the digital and physical spheres, which was not present before and which made it particularly well suited for users of 3D printers.

In this paper, we claim that the expansion of the market segment for personal 3D OS printers in recent years is strictly linked to the emergence of the Maker Movement. As the movement took off in 2011, with the increasing recognition of its influence among the media (see The Economist, 2011), and testified by the increasing number of public events organized (in 2011 the number of Maker Faire conventions doubled with respect to 2010 and continued to grow afterwards), also the sales of desktop low-cost 3D printers exhibited a positive turning point. According to Wohlers (2013), the number of personal 3D printers rose from 66 printers sold in 2007 to 23,265 units sold in 2011. As Figure (1) shows, the market segment for personal 3D printers registered an increase in sales of $290 \%$ between 2010 and 2011. As a matter of fact, in 2011 worldwide personal 3D printers' sales boomed for the first time after a long introductory phase, suggesting that something different had just occurred in the

\footnotetext{
${ }^{3}$ It must be stressed that the Maker Movement encompasses a wide spectrum of activities among which 3D printing, i.e. additive manufacturing, represents only a fraction of the numerous technologies used by the members of the community. These include several other types of technological tools that fit with the DIY mindset: one of these is, for instance, the well-known Arduino hardware and software solutions for digital devices.
} 
3D printing industry with the end of an industrial phase and the start of a new era (see Rayna and Striukova, 2016 for a similar view). The relevance of year 2011 is confirmed also by the results of the “3D printing survey 2013”, which specifically asked users of 3D printing to indicate the first year in which they started to use such printers. As shown by Figure (2) also in this case 2011 represents the year in which the number of users peaks and stabilizes around the levels of the next years. Indeed, users that started to use 3D printing from 2011 onwards represent 60 per cent of the total sample.

[Insert Figure 1]

[Insert Figure 2]

\section{Theory}

\subsection{Technological and symbolic innovations in the $3 D$ printing industry}

The symbolic value that (new) products bring along has been largely recognized and investigated in the management, marketing and sociology literatures, often adopting different theoretical lens, from post-modernism (van Raaij, 1993) to co-constructivism (Christiansen et al., 2010). Also the spectrum of dimensions of investigation has been quite large, ranging from product appearance's influence on the formation of symbolic content (Belk, 1988; Demirbilek and Sener, 2003; Bornemann et al., 2015), to reinforcement of human and cultural values through purchase decisions (Lamont and Molnàr, 2001; Lowe and Alpert, 2015). Dealing with a high-tech innovative product, in this paper we the notion of technological and symbolic innovation, originally introduced by Hirschman (1982). We apply this seminal distinction to the analysis of the diffusion of 3D printers. Categorizing 3D printing technology as both a technological and a symbolic innovation is helpful to understand the main features, as well as the evolution of the demand for 3D printers. We argue that the inclusion of a symbolic dimension into the use of (some type) of 3D printers, that especially accrued in 2011 through the rapid global development of the Maker Movement, is critical for understanding the more recent motivations behind 3D printing adoption. In line with Hirschman (1982) and subsequent 
empirical contributions in the management and marketing literature (e.g. Dickerson and Gentry, 1983), product innovations can be divided into two broad categories: technological and symbolic innovations. $^{4}$

Technological innovations are adopted for their performance characteristics and for their technical utility (Hirschman, 1982; Abernathy and Clark, 1985; Garcia and Calantone, 2002). They possess some tangible and technical features that did not exist previously in the same class of products. Most importantly, as Hirschman (1982) originally claimed, they do not bring along any "consumer desires for self-identity”.

Symbolic product innovations communicate new social meanings to already existing products. Meanings associated to a specific product do not remain constant and unchanged over time. Rather they evolve, since they are driven by broader changes in society and culture, which, on their turn, they also contribute to shape (Verganti, 2008; Christiansen et al., 2010). Thus, specific products may have been present in the economy since long time and yet be deemed as symbolic innovations at a certain point in time, due to modified consumers’ perceptions about the meanings associated with their usage. The main novelty consists therefore in the acquisition of intangible attributes that users and consumers associate to the use of that specific product (Rindova and Petkova, 2008). Such intangible attributes, which consumers associate to a product, do not stem from the physical nature of the item itself, but from the social meaning and implication one may draw from its usage (Hirschman, 1980, 1981). (Adoption of) symbolic innovations may imply new lifestyles that in turn may "serve, in effect, as reference groups" (Hirschman, 1982, p. 538) for other adopting consumers. Accordingly, symbolic innovations diffuse more for self-identity affirmation purposes, rather than for their technical and technology utility.

\footnotetext{
${ }^{4}$ Hirschman's argument here is analogous to the distinction recently put forward by Candi et al. (2016) in their study about customer codevelopment of new products, where authors differentiate innovation along utilitarian and hedonic radicalness. The symbolic attribute raised by Hirschman is also tangent to the concept of stylistic innovation where changes in the aesthetic characteristics can generate a new meaning arising from the consumption of an already existent product (Cappetta et al., 2006).
} 


\subsection{Hypotheses}

Building on this theoretical framework, we propose that 3D printers have evolved since their first introduction and they can now be considered as both a technological and symbolic innovation. The presence or not of the symbolic dimension strongly depends on the intellectual property rights regime adopted by suppliers for commercialization. This does not mean that some 3D printers have turned from technological to symbolic innovations. More specifically, the technological attribute still applies to 3D printers, irrespectively of whether they are proprietary or OS systems. However, in parallel with (and fuelled by) the development of the Maker Movement and similar communities of interest, a symbolic meaning was increasingly associated only to those 3D printers adopting an OS architecture. The birth and consolidation of the Maker Movement alongside the 3D printing sector produced an evolution in (some typologies of) 3D printers from being purely technological machines into something else, by making them embody a previously absent social meaning: the idea that everybody in modern advanced societies should be put in the condition to build everything for his/her own usage. This “universality” mission well-associates with the OS paradigm (Stallman et al., 2002).

Grounding on this premise and according to Hirschman (1982) and subsequent literature, we first posit that 3D proprietary printers' adoption should be primarily associated to the technological nature of $3 \mathrm{D}$ printing. The usage of technological innovations is often not immediate: since these innovations are "different” and “discontinuous”, they also often require specialized skills for their efficient use (Kessler and Chakrabarti, 1999). Following seminal contributions in the theory on innovation diffusion (e.g. Rogers, 1962; Robertson, 1967), it is legitimate to argue that first generations of technology-intensive products are often less user friendly and early adopters are typically very much technology-focused. Early adopters are generally more informed and more educated (Dickerson and Gentry, 1983) than the average population (and late adopters). Moreover, they are typically more financially-endowed, less price-sensitive and with higher time (opportunity) costs, thus more prone to choose market leading products, rather than willing to search for possible customizable alternatives. 
To sum up, our starting base-line research hypothesis is that more sophisticated, skilled and professional adopters should exhibit greater (even financial) interests/motivations in using 3D proprietary printers and be greatly interested in the technological performance of the innovation.

H1a: Being highly educated increases the likelihood of usage of 3D proprietary printers.

H1b: The usage of 3D proprietary printers appears as strictly related to work reasons.

As shown in the previous section, the rapid upsurge of entry of new 3D printers actors, mainly adopting OS hardware platforms, has revitalized the whole sector, and the industry literally took off starting from the year 2011. Symbolic attributes associated to the 3D printers, fostered by specific communities of interest on 3D printing, may have indeed played a role in this take off. In line with Hirschman (1982), we hypothesize that the birth and development of dedicated social groups (i.e. Maker Movement and related communities) have largely contributed to the association of additional social meanings to the 3D OS printers, turning them from a mere technological innovation into both a technological and symbolic one (e.g. see Jones, 2013; “The Maker Movement Manifesto”, 2014). ${ }^{5}$ Indeed, as shown by Pera and Viglia (2015) in a recent study on users of FabLabs (i.e. small-scale laboratories offering digital fabrication) in Spain and Italy, community affiliation motivations, rather than utilitarian purposes, were found to be associated with the subjective well-being of individuals involved in 3D printing. Here we claim that 3D OS printers are highly 'socially compatible' (see Cappetta et al., 2006, p. 1277) with communities of interest like Maker Movement and similar opinion groups. Accordingly, belonging to such groups also shapes the motivations to use 3D OS printers. At the same time, the use of a 3D OS printer could represent a sort of “entry-ticket” into these groups. Therefore, all in all, we expect that the adoption of 3D OS printers will be positively influenced by the belonging to this specific social community.

\footnotetext{
5 The Maker Movement Manifesto (Hatch, 2014) is all characterized by a strong emphasis on the philosophical and cultural meanings associated with the making of things.
} 
H2: Belonging to the Maker Movement increases the likelihood of usage of 3D OS printers.

Since 3D OS printers are increasingly becoming (also) symbolic innovations, users are more likely to adopt them because they share the same values of the community to which they wish to belong. As shown in the previous Sections, Maker Movement started gaining momentum especially in 2011, in co-occurrence with the first boom of sales of personal 3D printers. In this respect, we posit that the attribution of a symbolic meaning to the usage of 3D OS printers was particularly pronounced starting from the year 2011 onwards.

Specifically, we identify two stylized types of users of 3D OS printers and propose that the first was prevalent before 2011, when the symbolic attributes of 3D OS printers were less relevant, while the second was more common from 2011, when 3D OS printers were increasingly seen also as symbolic innovations, in line with the consolidation of new social groups and communities of users (see Figure 3).

\section{[Insert Figure 3]}

The first stylized type of 3D OS printer user is strongly linked with the DIY perspective: 3D OS printers are prevalently used by individuals to produce physical objects that serve solving a particular individual problem or need that is not satisfied by the mass market production. An user of this typology has been defined in the Maker Movement language as the "zero to maker user" (Deloitte, 2014): i.e., an individual chooses to switch from the consumption of a good to the invention of a new object that is better suited for his/her necessities. In order to produce the item, the individual uses low-cost 3D OS printer. This type of user does not necessarily belong to a specific social community and his/her activity can also be described as a sort of “modern (hobbyist) handicraft”. For this type of user, the symbolic dimension of 3D OS printers is not very relevant, since the use of 3D printers serves a specific, tangible and immediate scope and should not bring along any strong cultural value and intrinsic meaning associated to any specific social community. In this case in fact, the main motivation to use 3D OS printers is to produce new objects for one’s own personal use. 
Since we posit that symbolic attributes for 3D OS printers were particularly strong only starting from 2011, when new communities gained momentum, we expect this first type of users to be more common before 2011.

HЗa: The simple production of objects, without any specific adhesion to social and community ethical values, is more important among 3D OS printer users before 2011 rather than after.

The second type of user of 3D OS printer is instead more related with the symbolic and social dimension of the technology. For this type of user, working with a 3D OS printer mainly means being an active member of a specific community of users. From one side, usage (of 3D OS printers) translates for the user into a (self-)affirmation of adherence to the cultural values and principles that permeates the specific community of interest. Elliott (1997) and Elliott and Wattanasuwan (1998) refer to this psychological process as self-symbolism for defining the symbolic meaning of consumption direct to construct one's own self-identity. Belonging to the community also often means exerting effort in providing specific contributions and solutions to problems that have been defined as relevant by the community of interest (see Lakhani and von Hippel, 2003). The activity of this second type of users is not necessarily dedicated to the production of items that satisfy their own individual needs, but in most cases has more to do with upgrading and improving existing solutions already devised by members active in the community, through the production of functional models or prototypes. This type of users has often been labeled by observers interested in the 3D printing dynamics as “maker to maker” (Deloitte, 2014), in order to stress the fact that users collaborate and also access the expertise of others. Indeed, the importance to share knowledge and learn new skills through the active participation in the community is a fundamental feature of social groups such as the Maker Movement (see “The Maker Movement Manifesto”, Hatch, 2014). Since for this type of users the symbolic dimension of 3D OS printers is relatively more important, we expect them to be more common from 2011 onwards, rather than before, that is when 3D OS printers started to be considered also as symbolic innovations. Specifically, we expect that starting from 2011 users of 3D 
OS printers have given more importance to the acquisition of new skills through knowledge sharing activities and that they have used printers mainly to propose new solutions, create functional models and prototypes which can be useful for the community, rather than to simply produce objects for their own use.

H3b: Learning new skills and share knowledge is a more important motivation to use 3D OS printers from 2011 onwards rather than before.

H3c: The production of functional models and prototypes is more common among 3D OS printer users from 2011 onwards rather than before.

\section{Methodology}

\subsection{Data}

The empirical analysis relies on a unique novel dataset collected by the Peer to Peer Foundation ${ }^{6}$ -the “3D Printing survey 2013”- which contains detailed data on the characteristics of a sample of active users and potential interested consumers of 3D printers and 3D printer related services and was built through the means of a survey conducted in 2013. The survey, which is part of a longitudinal study conducted by the Peer-to-peer Foundation through annual surveys, was run in 2013 and it was directed to different types of groups of users and potential interested consumers, with the aim to be as inclusive as possible and be truly informative of the differentiated demand for 3D printers. The survey is, to our knowledge, one of the first attempts to map the universe of 3D printers users. The data collected includes overall answers from 283 respondents from 39 countries in the world, with a large majority coming from North America (47.1\%) and Europe (42.8\%) and a relatively lower

\footnotetext{
${ }^{6}$ The Peer to Peer foundation is an organization based in Amsterdam, Netherlands, for studying the impact of peer to peer technology on society. It was founded by Michel Bauwens, a theorist and researcher on the subject of technology, culture and business innovation.
} 
number from emerging countries such as China, India, Russia, Turkey and Brazil. ${ }^{7}$ The survey’s response rate from the different countries pretty much reflects worldwide figures of the 3D printing industry (e.g. Lentejas 2014) and has therefore the great advantage of providing a truly global and representative perspective on the use of 3D printers.

The dataset includes information about the individual characteristics of users (nationality, education, age), as well as detailed information about the specific brands of 3D printers they have used, their preferences with respect to the technological features of 3D printers and additional data concerning the activities for which the respondents use 3D printers for. Moreover, the dataset includes some specific questions related to whether or not users have joined specific social communities such as the Maker Movement. Finally, the dataset also reports the year in which respondents declared to have used a 3D printer for the first time: these data allow us to discriminate between recent users and more experienced ones.

\subsection{Dependent variables}

The “3D Printing survey 2013” asked respondents to indicate which brands of 3D printers they have used. Detailed information about brands of 3D printers used by adopters enabled us to distinguish users of 3D proprietary printers from users of 3D OS printers. Specifically, through publicly available information on the website of the specific producers and on 3D printers dedicated journals, we were able to classify 45 different brands of 3D printers into OS vs. proprietary printers. Typical examples of producers adopting proprietary systems are 3D Systems or Stratasys, while the most common 3D OS printers are RepRap or Ultimaker. On the basis of this information we built our two dependent variables: a dummy variable (Proprietary) equal to one if a user declared to have used at least one type of 3D proprietary printer and equal to zero otherwise, and another dummy (Open Source) equal to one if a user stated the use of at least one 3D OS printer and zero otherwise. ${ }^{8}$ In

\footnotetext{
${ }^{7}$ The survey in total includes 301 respondents, but 18 of them (5\%) did not provide complete answers to the questions of interest in our study, such as the level of education and age. For this reason, these individuals were excluded.

${ }^{8}$ In more recent years some OS producers have been acquired by established producers who instead adopt proprietary systems. An example is Makerbot, an OS producer which was acquired by Stratasys in 2013 and then started to sell new
} 
many cases users adopted both types of 3D printers, so the two adoption choices are not selfexcludable.

\subsection{Independent variables}

Education and Occupation. The respondents were asked to report their highest level of education. Accordingly, we built two dummy variables to measure the effect of education on the adoption choices of users: one dummy (Bachelor) that is equal to one for individuals with a bachelor degree as their highest degree and another dummy (Master or $\mathrm{PhD}$ ) that is equal to one for respondents who hold a master or a PhD. Furthermore, since we are also interested in the type of job of the respondents, we built another dummy variable (Work related) that is equal to one if the user declared to have a job related or partially related to 3D printing.

Maker Movement. The survey asked respondents to indicate whether they consider themselves as members of the so-called Maker Movement. This question is extremely relevant for the sake of our analysis, since it allows to identify individuals that belong to this specific community of users. We hence introduce a dummy variable (Maker Movement) that equals to one for those users who answered yes to this question and zero otherwise.

Skills development. The survey asked to indicate individuals’ motivations behind 3D printing usage through the means of a Likert scale. We selected the four questions that indicated the types of motivations that were more related to the sharing and development of new skills and created a new variable (Learn \& share skills) that includes for each respondent the average scores from the answers to these four questions. ${ }^{9}$ This variable measures how much each respondent uses 3D printers to learn

\footnotetext{
3D printer models with a proprietary system. The survey allows us to identify the brand but not the specific model respondents have actually used. Therefore in the few cases in which producers changed from an OS to a proprietary system we are not able to distinguish whether the respondents used an OS or a proprietary model of that specific producer. To check whether our empirical analysis could be affected by these specific cases, we identified the respondents who started to use 3D printers in 2013 -and stated that they used Makerbot printers- (8 individuals in total). We changed their status as adopters of proprietary 3D printers, instead of 3D OS printers. We then re-ran our empirical analyses using this new classification of users: the results showed that none of our findings was affected by this marginal change in the dependent variables.
}

${ }^{9}$ The four questions capture the following motivations behind participation in 3D printing projects: 1) willingness to develop tools and practices; 2) desire to learn new skills; 3) eagerness towards collaborative development; 4) pleasure in 
new skills and share them with the other members of the community. The interest for the development of new skills is also captured by another variable (Developer) that is equal to one for respondents that described themselves as developers (regardless of getting paid or not for this activity): the reference category in this case are the respondents who described themselves as end-users or as other typologies of users (such as academic researchers, entrepreneurs investing in 3D printing or people who engage in 3D printing as a hobby).

Activity. Finally, we are also interested in the type of activities that individuals use 3D printers for: we introduce two dummy variables that proxy two specific types of activities. The first is a binary variable (Production) that is equals one for those respondents that use 3D printers for the production of items, such as the custom or series production of parts, as well as the production of spare parts or covers of devices. The second dummy (Functional models/prototypes) proxies the use of 3D printers for activities that are more related to prototyping and the design of projects/functional models than to direct production: the dummy is equal to one for users that indicated that they use $3 \mathrm{D}$ printers to produce functional as well as presentation models.

Year of first adoption. The survey requested to report the year of first time use of 3D printers by respondents. As already said, this information allows us to distinguish relatively recent from experienced users of 3D printers: more specifically, the variable enables us to test our hypotheses concerning the evolution of 3D OS printers into (also) symbolic innovations in the most recent years.

Price effect. We use a binary variable that equals one for those users that stated that they would like that the 3D printing industry evolve towards more price convenient types of 3D printers (Price Convenience).

Other controls. We use a number of control variables in our model specifications. They include the age of each respondent (Age), a dichotomous variable to control for their gender (Male) and further information concerning their specific desiderata with respect to the future development of 3D

sharing one's own knowledge and skills with others. For each question the respondent had to indicate how much they agreed on the statement on the basis of a Likert scale (from 1 to 5). 
printers. More specifically we introduce 4 additional dummy variables equal to one for users that stated that they would like that 3D printing industry could evolve towards the use of new materials (Materials), a higher speed of 3D printers (Speed), a higher quality of the 3D printing processes (Quality), a more user-friendly typology of 3D printers (Easiness).

\subsection{Method of Analysis}

In this study, we are interested in identifying the factors that induce users of 3D printers to adopt either 3D proprietary printers or 3D OS printers, in order to check the validity of our hypotheses. Our dependent variables are the two dummy variables (Proprietary and Open Source) that indicate the adoption of the two different typologies of 3D printers. As customarily in this type of analysis, given the dichotomous nature of the dependent variables of interest, we adopt a probit analysis. However, the adoption of each of the two types of 3D printer is not mutually exclusive; users can adopt both types and, therefore, standard errors of the two probit equations might be correlated. This potential correlation requires to estimate the choice of using 3D proprietary printers or 3D OS printers simultaneously, using the bivariate probit maximum likelihood estimation method.

Our empirical specification is as follows:

$$
y_{i}^{s}=c+\sum_{j} \alpha_{j} E D U_{i j}+\beta M A K E R_{i}+\sum_{k} \gamma_{k} \operatorname{SKILLS}_{i k}+\sum_{l} \delta_{l} A C T I V_{i l}+\phi^{\prime} x+v_{i}
$$

where $s$ = proprietary, open source.

The bivariate probit estimates simultaneously the two different versions of equation (1): the first in which $y$ represents the probability to adopt 3D proprietary printers, and the second in which $y$ indicates the adoption of 3D OS printers. The independent variables are common in both specifications, in parentheses, we indicate for the test of which hypothesis these variables are instrumental for. EDU denotes a set of variables capturing the educational attainments and the occupational status of the respondents (hypotheses H1a and H1b), MAKER indicates membership to the Maker Movement (hypothesis H2), SKILLS represents a set of variables that indicate that the respondent uses 3D printers to develop skills and share them among a community of users (hypothesis 
H3b) and ACTIV denotes another set of variables that describes the types of activities that the respondents use 3D printers for (hypotheses H3a and H3c). Finally $x$ identifies the group of control variables included in the model, such as the age of the respondents, their gender and their preferences with respect to the future development of 3D printers.

An important factor that we need to take into account has to do with a potential sample selection issue: among the respondents of the survey not all individuals actually used a 3D printer, some of them were included in the surveyed sample because they were to some extent active among the community of 3D printers users, but they never really used a 3D printer and hence did not answer to many of the questions related to the use of 3D printers. These users are a quite limited portion of the sample (about $15 \%$ of the respondents), however in our analysis we want to check if the unobservables that affect the decision to use or not 3D printers are also correlated with the unobservables in equation (1), concerning the type of 3D printers adopted, either proprietary or OS. If that was the case, normal probit estimates without correction would be biased. Therefore, we ran a probit model which accounts for sample selection in order to check if that is a relevant issue or not. ${ }^{10}$ The results of the estimation of a probit with sample selection (Table A1 in the Appendix) show that indeed selection bias is not a problem in our specification. On the contrary, characteristics of users of 3D printers could well differ along the two investigated dimensions, i.e. proprietary vs. OS systems. In the next section we will focus on the results of the estimation of the bivariate probit models capturing the usage of these two different 3D printers.

\section{Results}

The choice between proprietary and Open Source 3D printers

\footnotetext{
${ }^{10}$ In the selection equation we included the variables for which we had information also for individuals who did not actually use 3D printers (education, age and gender), moreover since the selection equation needs to include at least one variable that is not present in the main equation, we added the nationality of the respondents as exclusionary restriction.
} 
Table (1) displays the correlation matrix and some descriptive statistics for our sample. The large majority of individuals are males (88\%). The average user's age is 35 years old. The share of individuals with a bachelor as the highest degree is $33 \%$, while those with a master or a $\mathrm{PhD}$ are almost $40 \%$. More than a half of sampled individuals (57\%) have a job that is related or partially related to 3D printing, while about 75\% declare themselves as members of the Maker Movement. Then, $48 \%$ of the individuals consider themselves as 3D printing developers, $75 \%$ mainly use 3D printers to produce physical items (such as series production, production of parts and covers) while $64 \%$ use 3D printing for the production of prototypes and functional models. About $40 \%$ of the respondents declare to have used a 3D printer for the first time before 2011, while the majority of them (60\%) started to use 3D printers from 2011 onwards, confirming that after 2011 3D printing became much more popular.

\section{[Insert Table 1]}

[Insert Table 2]

In Table (2) we present the estimates of the bivariate probit model, which will be instrumental for the testing of hypotheses 1 and 2. We estimated two different models: one only considers personal characteristics of respondents as independent variables (columns 1 and 3); the other also includes the independent variables that capture the type of activities carried on, the most wanted features on 3D printing and other controls (columns 2 and 4). In the estimates reported in columns (1) and (2) the dependent variable refers to eventual usage of a 3D proprietary printer, while in columns (3) and (4) the dependent variable is the adoption of 3D OS printers. In our estimates we report marginal effects: since the majority of our explanatory variables are dummy variables, we can interpret the coefficients as the increase (or decrease) in the probability to adopt each type of 3D printer that occurs when a variable switches from zero to one, everything else being equal. The strongly significant rho coefficient at the bottom of Table (2) indicates that the error terms of the two equations are strongly correlated, confirming the choice of our specification. 
The results are strongly in line with our hypothesis H1a: the coefficients that measure the level of education (Bachelor and Master or PhD) are positive and significantly different from zero in the 3D proprietary printer equation. Looking at the full-information model, having a bachelor degree increases by $16 \%$ the probability to adopt a $3 \mathrm{D}$ proprietary printer and holding a master or a $\mathrm{PhD}$ increases this probability by almost $18 \%$. On the contrary, the coefficients of the education variables are negative and statistically significant in the 3D OS printers model.

Hypothesis $H 1 b$, concerning the occupation level of the adopters, is instead not confirmed by the results (see columns 1 and 3): the coefficient of the variable that measures whether the individuals' work is related to $3 \mathrm{D}$ printing (Work related) is positive, but statistically not significant for 3D proprietary printers, indicating that working in a 3D related field does not significantly increase the probability of adopting 3D proprietary printers. On the contrary, working in a related field significantly decreases the probability to adopt 3D OS printers. These results do not change in columns (2) and (4), where we include additional controls, such as the type of activities in which users are engaged through 3D printing and the most wanted features for the development of 3D printers. Overall the results confirm that the adoption of technological innovations like the 3D proprietary printers is limited to more educated and skilled adopters, but not necessarily to individuals who also have work-related reasons to adopt 3D printers. Conversely, we notice that the users of 3D OS printers are in general less educated, they do not work in fields that are associated with 3D printing and are more likely to adhere to specific social communities such as the Maker Movement. Looking at the full-information model in column (4), belonging to the Maker Movement increases by 19\% the probability to adopt 3D OS printers. This confirms our hypothesis H2, according to which 3D OS printers are perceived also as symbolic innovations and therefore their adoption is strongly correlated with membership to social communities of users.

Among the other variables we find that there are not large differences in the activities for which proprietary and 3D OS printers are used for, nor specific age or gender significant differences are detected among the users of the two technologies. 


\section{The role of price}

A possible drawback of our empirical analysis lies in the fact that we analyze the adoption of 3D printers without controlling for the specific price of such printers. In some cases, price factors may be extremely important to determine the adoption of proprietary printers with respect to OS ones, which are usually cheaper. This is especially important if one looks at the birth and evolution of the 3D printing industry through the lens of Christensen's (1997) disruptive innovation framework. Such a framework predicts the emergence of innovators that target users that were not previously considered by established producers, because they could not afford the high level of prices of their existing products. In such a framework the adoption of OS 3D printers by the new set of users would merely be due to lowering prices (associated with lower technology attributes). Our hypotheses are instead that, while it is likely that lower prices influenced the adoption of OS 3D printers, this does not undermine the fact that also the creation of symbolic value affected their eventual adoption. To identify the effect of the symbolic value of 3D printers on their adoption conditional on their price we need to make sure that in our specification we control for prices effect. We do so in three ways. A first way to account for this factor is the inclusion of the price preferences of users as a control variable. If a user is generally concerned with the price of the 3D printers the inclusion of the dummy variable "Price Convenience” should allow us to identify the determinants of adoption, "net of” its specific price preferences. This variable is equal to one if in the 3D Survey the user stated that he/she wishes that 3D printer producers lower their price. The results in column (2) and (4) of Table (2) suggest that also when we control for price preferences the coefficient of Maker Movement, the variable that proxies the symbolic factors affecting the adoption of OS 3D printers, remains positive and significant.

Ideally a second, more precise methodology to account for price differences would be to analyze adoption only for categories of 3D printers with roughly similar prices. Unfortunately, this is not possible in our sample since we only know the brand of 3D printers and not the specific model used (in the case of Stratasys the price range goes from 6,000 \$ to 750,000 \$). A possible alternative to 
reduce price heterogeneity is to focus on $3 \mathrm{D}$ printers that use similar materials, since this should increase to a certain extent the price similarity between printers. In the Appendix we focus only on respondents that work with $3 \mathrm{D}$ printers that make use of polymers, which are the most common material used, rather than other materials (such as metal, cement or others). This reduces the number of observations by 36\%. The results however are extremely robust, as shown in Table A2: education is still positively associated with the adoption of 3D proprietary printers and, interestingly, also work related reasons become significant. Besides, belonging to the Maker Movement remains an important determinant of the adoption of OS 3D printers.

A third way to identify the effect of price on adoption is to combine our information about the first year of use of 3D printers by the respondents with a general index of 3D printer prices. If the adoption of OS 3D printers follows a typical price-based “disruptive” trajectory, one would expect that some users might have started to use OS 3D printers mainly because their price was low enough for them to afford it. If that is the case it would be plausible to find a negative impact of the average price of 3D printers (in the year of first adoption) on the probability to adopt an OS 3D printer. If price is indeed the only motivation behind the adoption, other factors related to the symbolic nature of this type of 3D printers would not instead influence their adoption. In order to test for this, we restrict our analysis to respondents that used either a proprietary or an Open Source 3D printer (excluding those that used both). Then we run the same probit specification of equation (1) including a new variable (Average Price) which indicates the average price of 3D printers in the year of first adoption. We use two different price indexes: one published by the Wohlers Report (2015) and the other provided by the consulting company IBISworld (Kempenich, 2018). Both indexes report a declining level of average prices over time, which is due, among other factors (technological innovation, prices of the intermediate goods used in the production), also to the emergence of low-cost OS 3D printing producers, which generally increased price competition in the market. We then build two Average Price variables, each based on one of the two indexes: the results in Table 3 show that the effect of Average Price is indeed negative, as we expected: as average prices decreased (driven by the new OS 
printers) new users started to adopt 3D printers, but only low-cost OS 3D printers. However, the results in Table 3 also show that, regardless of the price index used, the effect of price is not statistically significant from zero, hinting at a not very precise measurement of the effect. most importantly, the coefficients of our variables of interest (especially the Maker Movement variable) are not affected by the inclusion of this additional variable. This suggests that the importance of belonging to a community of users is still an important determinant of the adoption of OS 3D printers, even after accounting for their lower price.

The adoption of OS $3 D$ printers over-time

Next, we investigate more carefully the adoption of 3D OS printers and, on the basis of the information in the survey on the first year of adoption, we split our sample between users that started to use 3D printing before 2011 and those that used for the first time a 3D printer in 2011 or later. Table (4) reports the results of two probit models.

\section{[Insert Table 4]}

In both models the dependent variable is a binary variable that equals one for usage of 3D OS printers and zero for usage of 3D proprietary printers. In the first model (column 1) only individuals that started to use 3D printers before 2011 are included, while in the second model (column 2) only individuals that started to use 3D printers from 2011 onwards are included.

Results related to education and occupation are left rather unchanged with respect to those previously exposed in Table (2). We also find that belonging to the Maker Movement is a more relevant driver of the adoption of 3D OS printers for more recent users (starting from 2011), as testified by the estimated coefficient of the variable Maker Movement in column (2). The result appears in line with our expectations of a stronger symbolic content of 3D OS printers in recent years.

The inclusion into the model specification of the set of variables related to Development skills enables us to test hypotheses 3. According to hypothesis $H 3 a$, before 2011 the symbolic dimension of 3D OS printers should be less evident and users should be more likely to adopt a DIY approach, according to which they would simply use 3D printers to produce physical objects that satisfy their 
needs, when these necessities are not well satisfied by mass market production. Our empirical results in column (1) confirm our expectations. First, we find that the coefficient that indicates the adherence to the Maker Movement is not significantly different from zero before 2011. Secondly, the coefficient of the variable Production is positive and significant in column (1) and statically insignificant in column (2). The motivation related to the mere production of physical items leads to a $34 \%$ increase in the probability to adopt 3D OS printers before 2011, while it is negligible thereafter. At the bottom of Table (4) we also show a test of the equality of the Production coefficient across the two models, before 2011 and from 2011 onwards: the Wald test rejects the null hypothesis that the two coefficients are not significantly different $\left(\chi^{2}=3.29\right)$. Overall these results confirm hypothesis $H 3 a$ and highlight the prevalence of the so-called "zero to maker user" typology within the users of 3D OS printers before 2011.

In column (2) of Table (4) instead we check for the validity of Hypotheses $H 3 b$ and $H 3 c$. The second typology of users of 3D OS printers, i.e. the "maker to maker", should be relatively more prevalent starting from the year 2011 when 3D OS printers started to be perceived importantly also as symbolic innovations. Through the use of 3D OS printers, this type of user should give great importance to the development of new skills and competencies to be shared with the peer community of interest. The main 3D printer user's focus should move from the mere production of physical objects to the development of new solutions and ideas relevant for the community of interest. The results are in line with the hypotheses formulated. The coefficient of the variable that measures the importance for users of the development of new skills, as well as the sharing of competences with other users (Learn \& share skills), is positive and significant for the more recent users, while it is not significantly different from zero for users that adopted for the first time 3D OS printers before 2011. The Wald test of joint equality of the coefficients of Learn \& share skills strongly rejects the null hypothesis of no significant difference between the two coefficients $\left(\chi^{2}=4.77\right)$ : this confirms Hypothesis $H 3 b$. Moreover, while production was the main activity for users before 2011, the most recent users mainly use 3D OS printers for the implementation of functional models and 
presentations, that is for activities that are not strictly related with the production of physical objects, but rather with the introduction of prototypes and functional models that are able to offer answers to the existing issues identified by the communities of users. The Wald test of joint equality of the coefficients of Functional models/prototypes rejects the null hypothesis of no significant difference between the two coefficients $\left(\chi^{2}=5.84\right)$, confirming Hypothesis $H 3 c$. The results confirm that starting from the year 2011 the "maker to maker user" (Deloitte, 2014) has been the prevalent typology of user among the more recent wave of adopters of 3D OS printers.

\section{Conclusions}

This paper has analyzed the evolution of the global demand for 3D printers in the recent years. The 3D printing industry is undergoing a structural change in which established producers specialized in the supply of 3D printers to the Research \& Development labs of large companies are challenged by the emergence of a new wave of producers targeting directly final consumers, individual designers and engineers or small companies with low-cost and user-friendly 3D printers. This new wave of 3D printer producers further differentiate themselves from existing producers by adopting an OS business model for the commercialization of their products, while established producers mainly relied on a wholly proprietary system for the development of the technology. In recent years the market for the so-called “desktop 3D printers" has experienced extremely high rates of growth, in parallel with the birth and consolidation of communities of interest such as the so-called Maker Movement, with specific ethical values that well fit the OS paradigm. While this phenomenon has interested media and stakeholders, as well as the academic community, many features of this emerging market, as well as its future evolution, are still very little known. In particular very little is known about the characteristics of the demand for 3D printing, such as the specific preferences of users.

Our study is the first in the management literature which empirically investigates the factors that drive the adoption choices of the users of 3D printers. In our theoretical framework we propose that 
nowadays 3D printers can be classified as both technological and symbolic innovations, following the categorization originally introduced by Hirschmann (1982). More specifically while 3D proprietary printers share most of the features of technological innovations, since they are adopted mainly because of their technological features, the adoption of 3D OS printers depends also on more intangible motives, such as the adherence to a specific community of users and to its shared ethical values, such as the so-called Maker Movement. Grounding on this, the paper introduces some specific hypotheses concerning the motivations that drive individual users to adopt 3D proprietary printers (i.e. technologically-driven reasons) versus 3D OS printers (i.e. technological and symbolic rationales). Moreover, we further analyze the reasons underlying the adoption of 3D OS printers and check whether substantial differences occurred in this respect after the Maker Movement community gained momentum in 2011.

To empirically test our hypotheses we take advantage of a unique database provided by the Peer to Peer Foundation -the “3D Printing survey 2013”- which contains detailed information about the characteristics of a sample of international users of 3D printers. The empirical results confirm our hypotheses shaped on the technological and symbolic nature of 3D printers, when associated to a different intellectual property regime. Specifically, highly educated individuals are found to be more likely to adopt 3D proprietary printers; on the contrary the adherence to public opinion groups like the Maker Movement increases the likelihood of adopting 3D OS printers. Moreover, the results show that before 2011 the main motivation behind the adoption of 3D OS printers was the fabrication of objects for the satisfaction of personal needs, hence with little social and symbolic content. On the contrary, starting from 2011, the empirical analysis shows that the use of 3D OS printers is mainly driven by the belonging to the Maker Movement and by the adherence to the specific ethical values shared by its members, such as the importance to learn new skills and the willingness to share one's own personal contributions with the rest of the community of users.

\subsection{Implications}


The findings of this study shed new light on the recent evolution of the 3D printing industry, through an analysis of the composition of the demand for 3D printers and its internal heterogeneity. First we showed that there are substantial differences between the users of 3D proprietary and 3D OS printers and that the adoption of the latter are very much related with the adherence to specific community of users, whose common ethical values fit very well with the OS business model adopted by the new wave of producers. Moreover, we also showed that the symbolic and social motivations behind the adoption of 3D OS printers have increased in recent years, due to the rising importance of opinion groups like the Maker Movement.

These results sound relevant from both a theoretical and a managerial point of view. Product development literature often starts from the implicit assumption that specific market segments with precisely-defined boundaries may be identified and targeted by prospective innovators (see Christiansen et al. 2010 for a discussion). With reference to 3D printing, our study argues that this process of identification: a) is complex, as it is composed of multiple layers, involving technological features that interplay with different intellectual property regimes; b) could be rather unstable over time, not as a consequence of market forces or due to the natural obsolescence of technologies, but because of the parallel formation of communities of interest that attribute symbolic values to the purchase of products; c) is affected by exogenous non-economic forces which are (at least in part) out of control of the firms (like the birth and development of the Maker Movement). In this respect, if the "technological game" is often won by those managers who are better capable to loom out of the “technological fog” surrounding new products (Arthur, 1996), our analysis strongly emphasizes that the analysis on the technological features that best suit specific typologies of consumers, cannot be disjointed by a careful analysis on the symbolic and sociological implications that these specific features exert on potential buyers. Of course, this addition makes the technological landscape (and managers' task) even more complicated and the outcome of their actions and strategies in this modified scenario even more uncertain than what is generally perceived. 
In this respect our analysis offers interesting advices to 3D proprietary printers producers entering the market segment of desktop 3D printers, where OS producers are still predominant. Our findings suggest that established companies should be eager to (at least partly) adapt their business models and take into account the specific preferences of the users of this specific market segment. Simply introducing low-cost 3D printers, while retaining their original fully proprietary business model, might indeed not be sufficient to gain credibility among users. In this respect the recent wave of acquisitions of 3D OS printers companies by large established producers of professional 3D printers ${ }^{11}$ suggests that this has been partially acknowledged by the latter actors. Our analysis also suggests that simply acquiring OS producers and convert them to the proprietary model may be a risky strategy, as shown for example by the negative hype originated after the switch of Makerbot from an OS to a proprietary regime, after its acquisition by Stratasys in 2013 (Rayna and Striukova, 2016). Our work offers a theoretically-sounded and an empirically-based justification for such managerial advices, and in line with the concept of social compatibility (see Cappetta et al., 2006), stresses the importance from a managerial perspective of ensuring coherence between the social meanings embodied in a product (also through the management of intellectual property rights) and a nascent community. Importantly, our analysis also offers new insights into the relationship between OS and related communities of interest. If OS is a relatively new (albeit consolidated) way of managing intellectual property rights in the technological arena that may spur a new product's acceptance among consumers, its adoption by firms may turn out to be successful only when it is able to originate and then consolidate new opinion groups and sociological movements which attach a new meaning to that specific product. If the birth of these communities of interests may in most cases be exogenous to a specific firm’s behavior, nevertheless, the ability to recognize communities’ insurgence and affirmation in societies might turn out to be an important discriminating factor for a successful NPD strategy.

\footnotetext{
${ }^{11}$ See for instance the acquisition of the 3D OS producers Bits from Bytes and ZCorp by 3D System respectively in 2010 and 2012, as well as the purchase of MakerBot by Stratasys in 2013 (Wohlers 2012).
} 


\subsection{Future Research}

We believe that our research constitutes an important contribution in the investigation of how communities of interest and social movements may shape new meanings associated to pre-existing technologies and make these technologies symbolically novel. Our study represents only a first step in this direction, while it opens interesting avenues for future research. Indeed, since the attribution of symbolic value to already existing products often leads to the emergence of new market segment, our analysis offers interesting insights also in combination with other existing frameworks that explain similar patterns, such as the disruptive innovation framework. Disruptive innovation theory predicts the emergence of innovators that target low-end users (or even new users that were not served before) of existing products of incumbent firms. In such a theoretical framework the main motivation for the mass adoption of these new low-price products is their lower cost, in combination with the need for a lower number of technological attributes by such users (Bower and Christensen, 1995; Christensen, 1997). In this respect our analysis shows that in some cases the association of a symbolic value to such new products by communities of users, as in the case of OS 3D printers, can be another important factor driving the emergence of low-cost alternatives. Future research may analyze the extent to which the emergence of other disruptive technologies (such as smartphones, Airbnbn, Blockchain Technology, etc.) is influenced and boosted also by new symbolic attributes to existing products or services, and whether this occurs through the creation of community of users.

From a management perspective it would also be relevant to analyze more in details how firms' NPD strategies adapt and co-evolve over time along with the social movements dynamics, and if firms’ strategies are able to influence communities’ evolution. The 3D printers industry, with all its disruptive technologic and symbolic potential, represents an ideal-test for investigating these issues. Lastly, with the spread of 3D printing on a more large scale, and the alleged availability of more detailed datasets, our theoretical and empirical investigation here performed could be extended in the search of which fine-grained users' characteristics are relevant for explaining adoption of different typologies of printers. In this respect, a more micro-level analysis on how communities inform, shape 
and influence product market categories would represent an important aspect which is worth of exploration in the 3D printing industry. 


\section{References}

Abernathy, W.J. and Clark, K. 1985. Mapping the Winds of Creative Destruction. Research Policy 14(1): 3-22.

Anderson, C. 2012. Makers. The New Industrial Revolution. NY: Crown Pub Editions.

Arthur, W. B. 1996. Increasing returns and the new world of business. Harvard Business Review 74(4): 100-109.

Baldwin, C., C. Hienerth and von Hippel, E. 2006. How user innovations become commercial products: A theoretical investigation and case study. Research Policy 35(9): 1291-1313.

Belk, R.W. 1988. Possessions and the extended self. Journal of Consumer Research 15(2): 139-68.

Berman, B. 2012. 3-D printing: The new industrial revolution. Business Horizons 55(2): 155-162.

Bornemann, T., Schöler, L. and Homburg, C. 2015. In the Eye of the Beholder? The Effect of Product Appearance on Shareholder Value. Journal of Product Innovation Management, 32(5): 704-715.

Bower, J. L. and Christensen, C. M. 1995 Disruptive Technologies: Catching the Wave. Harvard Business Review 73(1): 43-53.

Candi, M., van den Ende, J. and Gemser, G. 2016. Benefits of Customer Codevelopment of New Products: The Moderating Effects of Utilitarian and Hedonic Radicalness. Journal of Product Innovation Management 33(4): 418-434.

Cappetta, R., Cillo, P. and Ponti, A. 2006. Convergent Designs in Fine Fashion: An Evolutionary Model for Stylistic Innovation. Research Policy 35(9): 1273-1290.

Christensen, C. M. 1997. The Innovator's Dilemma: When New Technologies Cause Great Firms to Fail, Harvard Business School Press, Boston.

Christiansen, J.K., Claus, J.V., Gasparin, M., Storm-Nielsen, D. and Vinther, E.J. 2010. Living Twice: How a Product Goes through Multiple Life Cycles. Journal of Product Innovation Management 27(6): 797-827.

Dahlander, L., Frederiksen, L., and Rullani, F. 2008. Online Communities and Open Innovation. Industry and Innovation. 15(2): 115-123.

De Jong, J.P.J. and De Bruijn, E. 2013. Innovation Lessons From 3-D Printing. MIT Sloan Management Review 54(2): 43-52.

Dell'Era, C. 2010. Art for Business: Creating Competitive Advantage through Cultural Projects. Industry and Innovation, 17(1): 71-89.

Dell'Era, C. and Verganti, R. 2009. The impact of international designers on firm innovation capability and consumer interest. International Journal of Operations \& Production Management 29(9): 870-893.

Deloitte 2014. A Movement in the Making. Texas-US: Deloitte University Press. 
Demirbilek, O. and Sener, B. 2003. Product design, semantics and emotional response. Ergonomics 46(14): 1346-1360.

Dickerson, M.D. and Gentry, J.W. 1983. Characteristics of Adopters and Non-Adopters of Home Computers. Journal of Consumer Research 10(2): 225-235.

Elliott, R. 1997. Existential Consumption and Irrational Desire. European Journal of Marketing 34(4): 285-296.

Elliott, R. and Wattanasuwan, K. 1998. Consumption and the Symbolic Project of the Self. In European Advances in Consumer Research, eds. B. G. Englis and A. Olofsson, Provo, 17-20. UT : Association for Consumer Research.

Ford, S., Mortara, L. and Minshall, T. 2016. The Emergence of Additive Manufacturing: Introduction to the Special Issue. Technological Forecasting \& Social Change 102: 156-159.

Garcia, R. and Calantone, R. 2002. A critical look at technological innovation typology and innovativeness terminology: a literature review. Journal of Product Innovation Management 19(2): 110-132.

Hatch, M. 2014. The Maker Movement Manifesto. McGraw-Hill Education.

Hirschman, E.C. 1980. Attributes of Attributes and Layers of Meaning. Advances in Consumer Research 7(1): 7-12.

Hirschman, E.C. 1981. Commonality and Idiosyncracy in Popular Culture: an Empirical Examination of the 'Layers of Meaning' Concept. In Symbolic Consumer Behavior, eds. E. C. Hirschman and M. B. Holbrook, 29-34. New York, NY: Association for Consumer Research.

Hirschman, E.C. 1982. Symbolism and technology as sources for the generation of innovations. Advances in Consumer Research 9: 537-541.

Kempenich, B. 2018. ProcurementIQ Report: 3D Printers, IbisWorld.

Jones, S.E. 2013. The Emergence of Digital Humanities. Routledge.

Kessler, E.H. and Chakrabarti, A.K. 1999. Speeding up the pace of new product development. Journal of Product Innovation Management 16(3): 231-247.

Kietzmann, J., Pitt, L. and Berthon, P. 2015. Disruptions, decisions, and destinations: Enter the age of 3-D printing and additive manufacturing. Business Horizons 58(2): 209-215.

Kostakis, V., Niaros, V and Giotitsas, C. 2015. Open Source 3D Printing as a Means of Learning: an Educational Experiment in two High Schools in Greece. Telematics and Informatics 32: 118-128.

Kyriakou H. and Nickerson, J.V. 2014. Collective Innovation in Open Source Hardware. Collective Intelligence, 2014 Conference Proceedings. Available at SSRN: http://ssrn.com/abstract=2421332 or http://dx.doi.org/10.2139/ssrn.2421332. 
Lakhani, K.R. and von Hippel, E. 2003. How open source software works: "free” user-to-user assistance. Research Policy 32(6): 923-943.

Lamont, M. and Molnàr, V. 2001. How blacks use consumption to shape their collective identity: Evidence from marketing specialists. Journal of Consumer Culture 1: 31-45.

Lentejas, R.J. 2014. These Four Countries are Emerging 3D Printing Giants. Inside3Dp Report. Available at: http://www.inside3dp.com/four-countries-emerging-3d-printing-giants/.

Lerner, J., and Tirole, J. 2002. Some simple economics of open source. Journal of Industrial Economics, 50(2): 197-234.

Lipson, H. and Kurman, M. 2013. Fabricated: The New World of 3D Printing. UK: Wiley.

Lowe, B. and Alpert, F. 2015. Forecasting consumer perception of innovativeness. Technovation 4546: 1-14.

Malone, E. and Lipson, H. 2007. Fab@Home: the personal desktop fabricator kit. Rapid Prototyping Journal 13(4): 244-255.

Mellor, S., Hao, L. and Zhang, D. 2014. Additive manufacturing: A framework for implementation. International Journal of Production Economics 149: 194-201.

Millar, C.C.J.M. 2010. Technology standards and increasing returns: Microsoft versus Nokia and Linux. International Journal of Technology Management, 49(4): 357-369.

Moilanen, J. and Vadén, T. 2013. 3D printing community and emerging practices of peer production. First Monday, 18(8).

Pearce, J.M. 2012. Building Research Equipment with Free, Open-Source Hardware. Science 337: 1303-1304.

Pera, R., and Viglia, G. 2015. Turning ideas into products: subjective well-being in co-creation. The Service Industries Journal 35(7-8): 388-402.

Piller, F. T., Weller, C. and Kleer, R. 2015. Business Models with Additive Manufacturing Opportunities and Challenges from the Perspective of Economics and Management. In Advances in Production Technology, ed. C. Brecher. Springer International Publishing.

Rayna, T. and Striukova, L. 2016. From Rapid Prototyping to Home Fabrication: How 3D Printing is Changing Business Model Innovation. Technological Forecasting and Social Change 102: 214224.

Rindova, V.P. and Petkova, A.P. 2008. When Is a New Thing a Good Thing? Technological Change, Product Form Design, and Perceptions of Value for Product Innovations. Organization Science 18(2): 217-232.

Robertson, T.S. 1967. The Process of Innovation and the Diffusion of Innovations. Journal of Marketing 31(1): 14-19.

Rohlfs, J.H. 2001. Bandwagon Effects in High-Technology Industries. Cambridge: MIT Press. 
Rogers, E. M. 1962. Diffusion of Innovations. New York: Free Press.

Sells, E., Bailard, S., Smith, Z., Bowyer, A. and Olliver, V. 2009. RepRap: The Replicating Rapid Prototyper-maximizing customizability by breeding the means of production. In Handbook of Research in Mass Customization and Personalization, Volume 1: Strategies and Concepts, eds. F. T. Pillar and M. M. Tseng, 568-580. New Jersey: World Scientific.

Singh, A., Bansal, R.K., Jha, N. 2015. Open source software vs. proprietary software. International Journal of Computer Applications 114(18): 1-6.

Stallman, R. 1999. The GNU Operating System and the Free Software Movement, in C. DiBona, S. Ockman and M. Stone (eds), Open Sources: Voices from the Open Source Revolution (O'Reilly, Sebastopol, California), 53-70.

Stallman, R., Lessig, L. and Gay, J. 2002. Free Software, Free Society: Selected Essays of Richard M. Stallman, Free Software Foundation, Boston, US.

The Economist 2011. Print me a Stradivarius: How a new manufacturing technology will change the world. Available at: http://www.economist.com/node/18114327.

Van Raaij, W.F. 1993. Postmodern consumption. Journal of Economic Psychology 14: 541-563.

Verganti, R. 2008. Design, Meanings, and Radical Innovation: A Metamodel and a Research Agenda. Journal of Product Innovation Management 25(5): 436-456.

West, J. and Kuk G. 2016. The Complementarity of Openness: How MakerBot Leveraged Thingverse in 3D Printing. Technological Forecasting \& Social Change 102: 169-181.

West, J. and Lakhami, K.R. 2008. Getting Clear About Communities in Open Innovation. Industry and Innovation, 15(2): 223-231.

Wittbrodt, B.T., Glover, A.G., Laureto, J., Anzalone, G.C., Oppliger, D., Irwin, J.L. and Pearce, J.M. 2013. Life-cycle economic analysis of distributed manufacturing with open-source 3-D printers. Mechatronics 23(6): 713-726.

Wohlers Associates. 2012. Wohlers Report 2012: Additive manufacturing and 3D printing state of the industry. Wohlers Associates.

Wohlers Associates. 2013. Wohlers Report 2013: Additive manufacturing and 3D printing state of the industry. Wohlers Associates.

Wohlers Associates. 2015. Wohlers Report 2015: Additive manufacturing and 3D printing state of the industry. Wohlers Associates. 
Figures and Tables

Figure 1. Sales of “personal” 3D printers (units sold)

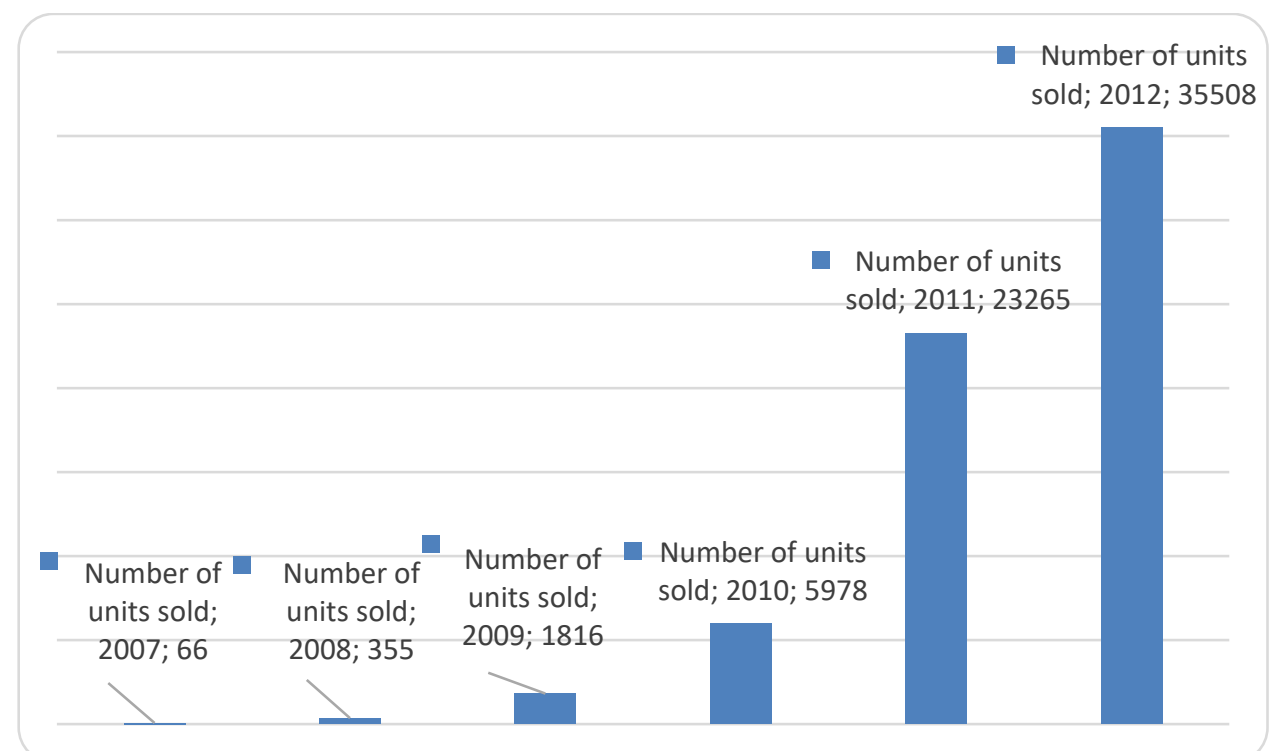

Source: Wohlers Associates (2013)

Figure 2. First year of adoption among users of 3D printers

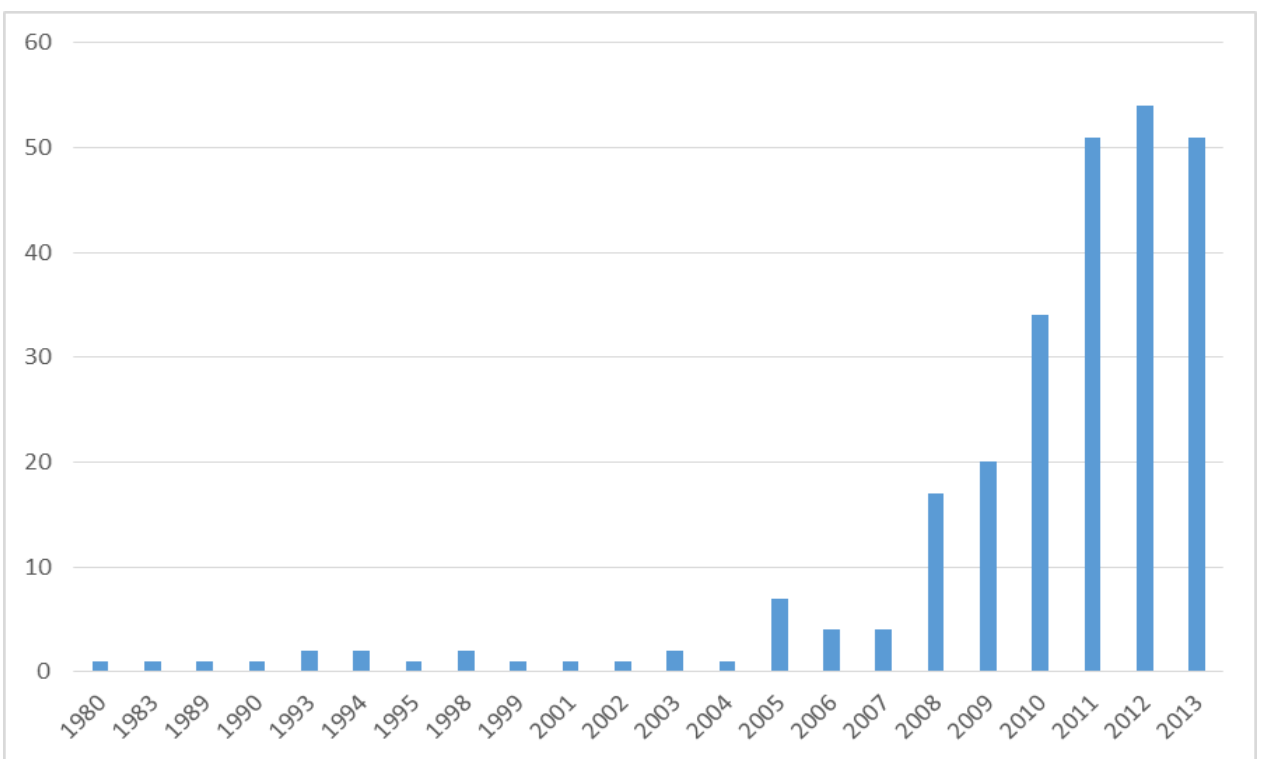

Source: 3D Printing Survey (2013) 
Figure 3. The shift of 3D OS printers into symbolic innovations

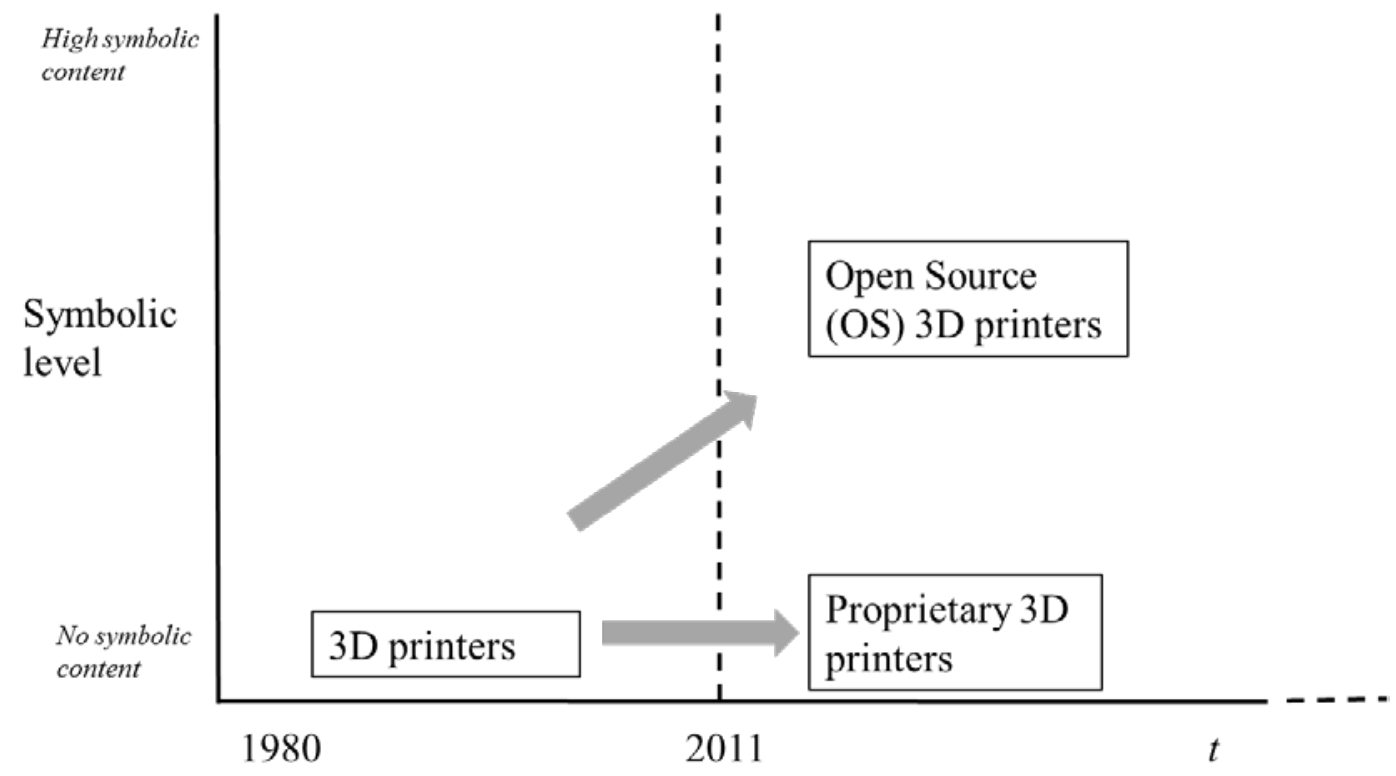


Table 1. Descriptive statistics and correlation matrix.

\begin{tabular}{|c|c|c|c|c|c|c|c|c|c|c|c|c|c|c|c|c|c|c|}
\hline & & 1 & 2 & 3 & 4 & 5 & 6 & 7 & 8 & 9 & 10 & 11 & 12 & 13 & 14 & 15 & 16 & 17 \\
\hline 1 & Proprietary 3D printer & 1 & & & & & & & & & & & & & & & & \\
\hline 2 & Open source 3D printer & -0.241 & 1 & & & & & & & & & & & & & & & \\
\hline 3 & Bachelor & 0.017 & -0.034 & 1 & & & & & & & & & & & & & & \\
\hline 4 & Master or PhD & 0.176 & -0.089 & -0.552 & 1 & & & & & & & & & & & & & \\
\hline 5 & Age & 0.013 & -0.048 & 0.035 & 0.025 & 1 & & & & & & & & & & & & \\
\hline 6 & Male & -0.042 & 0.132 & 0.047 & -0.157 & 0.235 & 1 & & & & & & & & & & & \\
\hline 7 & Work related & 0.267 & 0.058 & -0.037 & 0.144 & -0.123 & -0.129 & 1 & & & & & & & & & & \\
\hline 8 & Maker Movement & -0.035 & 0.148 & 0.074 & -0.077 & 0.029 & -0.037 & -0.041 & 1 & & & & & & & & & \\
\hline 9 & Learn \& Share skills & -0.076 & 0.013 & -0.064 & 0.157 & 0.001 & 0.003 & -0.084 & 0.079 & 1 & & & & & & & & \\
\hline 10 & Developer & -0.027 & 0.324 & 0.059 & -0.033 & -0.014 & 0.066 & 0.147 & 0.203 & 0.008 & 1 & & & & & & & \\
\hline 11 & Production & 0.015 & 0.228 & 0.057 & -0.050 & 0.076 & 0.217 & 0.012 & 0.105 & -0.051 & 0.094 & 1 & & & & & & \\
\hline 12 & Functional models/prototypes & 0.116 & 0.205 & 0.014 & -0.065 & 0.060 & 0.240 & 0.042 & 0.142 & -0.101 & 0.252 & 0.227 & 1 & & & & & \\
\hline 13 & New materials & 0.034 & 0.025 & 0.064 & 0.048 & 0.015 & 0.114 & -0.043 & 0.179 & 0.102 & 0.096 & 0.139 & 0.221 & 1 & & & & \\
\hline 14 & Speed & 0.015 & 0.101 & -0.013 & 0.080 & 0.012 & 0.007 & 0.033 & 0.046 & 0.123 & -0.041 & 0.071 & 0.035 & 0.095 & 1 & & & \\
\hline 15 & Quality & 0.105 & -0.020 & -0.054 & 0.076 & 0.092 & 0.178 & 0.029 & 0.102 & 0.183 & -0.061 & 0.020 & 0.136 & 0.140 & 0.234 & 1 & & \\
\hline 16 & Easiness & -0.007 & 0.204 & -0.064 & 0.036 & -0.061 & 0.078 & 0.053 & 0.055 & 0.150 & 0.086 & 0.009 & -0.065 & -0.010 & 0.177 & 0.147 & 1 & \\
\hline 17 & Price Convenience & 0.036 & -0.173 & 0.027 & -0.051 & -0.100 & -0.063 & 0.001 & 0.213 & 0.163 & -0.080 & -0.223 & -0.045 & 0.071 & 0.178 & 0.143 & 0.059 & 1 \\
\hline \multicolumn{2}{|c|}{ Mean } & 0.343 & 0.514 & 0.338 & 0.392 & 35.850 & 0.888 & 0.571 & 0.758 & 2.157 & 0.483 & 0.750 & 0.646 & 0.696 & 0.504 & 0.608 & 0.379 & 0.438 \\
\hline \multicolumn{2}{|c|}{ Std. Dev. } & 0.475 & 0.500 & 0.474 & 0.489 & 10.453 & 0.317 & 0.496 & 0.429 & 1.251 & 0.501 & 0.434 & 0.479 & 0.461 & 0.501 & 0.489 & 0.486 & 0.497 \\
\hline \multicolumn{2}{|c|}{ Min } & 0 & 0 & 0 & 0 & 16 & 0 & 0 & 0 & 0 & 0 & 0 & 0 & 0 & 0 & 0 & 0 & 0 \\
\hline \multicolumn{2}{|c|}{ Max } & 1 & 1 & 1 & 1 & 74 & 1 & 1 & 1 & 5 & 1 & 1 & 1 & 1 & 1 & 1 & 1 & 1 \\
\hline
\end{tabular}


Table 2. The adoption of proprietary or 3D OS printers

\begin{tabular}{|c|c|c|c|c|}
\hline \multirow{2}{*}{ VARIABLES } & \multicolumn{2}{|c|}{ Proprietary } & \multicolumn{2}{|c|}{ Open Source } \\
\hline & & & & \\
\hline Bachelor & $\begin{array}{c}0.134 * * \\
(0.062)\end{array}$ & $\begin{array}{c}0.159 * * \\
(0.067)\end{array}$ & $\begin{array}{c}-0.182 * * \\
(0.072)\end{array}$ & $\begin{array}{c}-0.205^{* * *} \\
(0.077)\end{array}$ \\
\hline Master or Phd & $\begin{array}{l}0.147^{* *} \\
(0.059)\end{array}$ & $\begin{array}{c}0.177 * * * \\
(0.060)\end{array}$ & $\begin{array}{c}-0.220^{* * *} \\
(0.069)\end{array}$ & $\begin{array}{c}-0.255^{* * *} \\
(0.072)\end{array}$ \\
\hline Work related & $\begin{array}{c}0.038 \\
(0.043)\end{array}$ & $\begin{array}{c}0.038 \\
(0.044)\end{array}$ & $\begin{array}{c}-0.133^{* *} \\
(0.062)\end{array}$ & $\begin{array}{c}-0.151^{* *} \\
(0.064)\end{array}$ \\
\hline Maker Movement & $\begin{array}{c}-0.145^{* * *} \\
(0.055)\end{array}$ & $\begin{array}{c}-0.179 * * * \\
(0.062)\end{array}$ & $\begin{array}{c}0.151 * * \\
(0.061)\end{array}$ & $\begin{array}{c}0.187 * * * \\
(0.066)\end{array}$ \\
\hline Age & $\begin{array}{c}0.001 \\
(0.002)\end{array}$ & $\begin{array}{c}0.001 \\
(0.002)\end{array}$ & $\begin{array}{l}-0.001 \\
(0.003)\end{array}$ & $\begin{array}{c}-0.001 \\
(0.003)\end{array}$ \\
\hline Male & $\begin{array}{l}-0.069 \\
(0.073)\end{array}$ & $\begin{array}{l}-0.020 \\
(0.074)\end{array}$ & $\begin{array}{c}0.062 \\
(0.087)\end{array}$ & $\begin{array}{c}0.007 \\
(0.103)\end{array}$ \\
\hline Activity & & & & \\
\hline Production & & $\begin{array}{l}-0.051 \\
(0.054)\end{array}$ & & $\begin{array}{c}0.018 \\
(0.074)\end{array}$ \\
\hline Functional models/prototypes & & $\begin{array}{l}-0.066 \\
(0.050)\end{array}$ & & $\begin{array}{c}0.006 \\
(0.069)\end{array}$ \\
\hline Wanted Features & & & & \\
\hline Price Convenience & & $\begin{array}{c}0.135^{* * *} \\
(0.050)\end{array}$ & & $\begin{array}{c}-0.136 * * \\
(0.066)\end{array}$ \\
\hline New Materials & & $\begin{array}{l}-0.027 \\
(0.048)\end{array}$ & & $\begin{array}{c}0.047 \\
(0.067)\end{array}$ \\
\hline Speed & & $\begin{array}{c}-0.097 * * \\
(0.046)\end{array}$ & & $\begin{array}{l}0.106^{*} \\
(0.064)\end{array}$ \\
\hline Quality & & $\begin{array}{c}0.050 \\
(0.047)\end{array}$ & & $\begin{array}{l}-0.076 \\
(0.070)\end{array}$ \\
\hline Easiness & & $\begin{array}{c}-0.145^{* * *} \\
(0.043)\end{array}$ & & $\begin{array}{l}0.128^{*} \\
(0.067)\end{array}$ \\
\hline Observations & 240 & 240 & 240 & 240 \\
\hline Rho & -0.341 & -0.429 & -0.341 & -0.429 \\
\hline p-value $\left(\chi^{2}\right)$ & 0.002 & 0.000 & 0.002 & 0.000 \\
\hline log-likelihood & -291.1 & -262.5 & -291.1 & -262.5 \\
\hline
\end{tabular}


Table 3. The adoption of Open Source 3D printers: robustness checks on price effects

(1)

Open source
(2)

Open source

VARIABLES

Average price

$-0.255$

$-0.457$

(0.219)

(0.319)

Bachelor

$-0.261^{* *}$

$-0.233^{* *}$

Master or Phd

(0.119)

(0.117)

$-0.329 * * *$

$-0.292^{* *}$

Work related

(0.118)

(0.121)

$-0.061$

$-0.055$

(0.081)

(0.084)

Maker Movement

$0.334 * * *$

$0.305^{* * *}$

(0.114)

(0.116)

Age

$-0.004$

$-0.003$

(0.005)

(0.004)

Male

0.005

0.006

(0.131)

(0.129)

Activity

Production

0.048

0.040

(0.108)

(0.104)

Functional models/prototypes

0.112

0.131

(0.098)

(0.100)

\section{Wanted Features}

Price Convenience

$$
-0.241^{* * *}
$$

$-0.228 * * *$

New materials

(0.088)

$-0.034$

$-0.027$

(0.098)

(0.096)

Speed

$0.176^{* *}$

$0.143 *$

$(0.082)$

(0.082)

Quality

$-0.064$

$-0.058$

(0.085)

(0.087)

Easiness

$0.219 * * *$

$0.194 * *$

(0.080)

(0.082)

\begin{tabular}{lcc} 
Observations & 146 & 141 \\
log-likelihood & -72.19 & -69.46 \\
Pseudo Rsquared & 0.219 & 0.206 \\
\hline
\end{tabular}

The models are estimated with a probit: marginal effects on the probability to use OS 3D printers are reported. Users that use both OS and proprietary 3D printers are excluded. In column (1) the variable Average Price is built using the price index provided by Wohlers and associates. In column (2) the variable Average Price is built using the price index provided by IBISWorld. S. e. in round brackets are clustered at the individual level. Significance level: *** $p<0.01, * * p<0.05,{ }^{*} p<0.1$ 
Table 4. The new wave of Open Source

(1)

Before 2011
(2)

From 2011

\begin{tabular}{|c|c|c|}
\hline Bachelor & $\begin{array}{c}-0.367 * * \\
(0.175)\end{array}$ & $\begin{array}{c}-0.259^{* *} \\
(0.109)\end{array}$ \\
\hline Master or Phd & $\begin{array}{c}-0.389 * * * \\
(0.145)\end{array}$ & $\begin{array}{l}-0.187 * \\
(0.111)\end{array}$ \\
\hline Work related & $\begin{array}{c}0.130 \\
(0.130)\end{array}$ & $\begin{array}{l}-0.068 \\
(0.074)\end{array}$ \\
\hline Maker Movement & $\begin{array}{c}0.072 \\
(0.156)\end{array}$ & $\begin{array}{l}0.218^{* *} \\
(0.099)\end{array}$ \\
\hline Age & $\begin{array}{l}-0.009 * \\
(0.005)\end{array}$ & $\begin{array}{c}0.002 \\
(0.004)\end{array}$ \\
\hline Male & $\begin{array}{c}0.002 \\
(0.189)\end{array}$ & $\begin{array}{c}0.080 \\
(0.142)\end{array}$ \\
\hline \multicolumn{3}{|l|}{ Activity } \\
\hline Production & $\begin{array}{c}0.338 * * * \\
(0.119)\end{array}$ & $\begin{array}{c}0.037 \\
(0.096)\end{array}$ \\
\hline Functional models/prototypes & $\begin{array}{l}-0.089 \\
(0.130)\end{array}$ & $\begin{array}{c}0.292 * * * \\
(0.091)\end{array}$ \\
\hline \multicolumn{3}{|l|}{ Skills Development } \\
\hline Learn \& Share skills & $\begin{array}{l}-0.038 \\
(0.049)\end{array}$ & $\begin{array}{c}0.083^{* * *} \\
(0.032)\end{array}$ \\
\hline Developer & $\begin{array}{c}0.409 * * * \\
(0.100)\end{array}$ & $\begin{array}{r}0.210^{* * *} \\
(0.079)\end{array}$ \\
\hline \multicolumn{3}{|l|}{ Wanted Features } \\
\hline Price Convenience & $\begin{array}{l}-0.187 \\
(0.143)\end{array}$ & $\begin{array}{c}-0.171^{* *} \\
(0.083)\end{array}$ \\
\hline New Materials & $\begin{array}{l}-0.079 \\
(0.121)\end{array}$ & $\begin{array}{c}0.115 \\
(0.091)\end{array}$ \\
\hline Speed & $\begin{array}{c}0.294^{* * *} \\
(0.106)\end{array}$ & $\begin{array}{c}0.108 \\
(0.083)\end{array}$ \\
\hline Quality & $\begin{array}{c}0.052 \\
(0.135)\end{array}$ & $\begin{array}{l}-0.049 \\
(0.080)\end{array}$ \\
\hline Easiness & $\begin{array}{c}0.242^{* *} \\
(0.096)\end{array}$ & $\begin{array}{l}0.133^{*} \\
(0.080)\end{array}$ \\
\hline
\end{tabular}

\begin{tabular}{|c|c|c|}
\hline \\
\hline \multicolumn{3}{|c|}{$\begin{array}{l}\text { Joint equality Wald test of coefficients (chi-square) } \\
\text { Production }\end{array}$} \\
\hline \multirow{2}{*}{\multicolumn{2}{|c|}{$\begin{array}{l}\text { p-value } \\
\text { Functional models/prototypes }\end{array}$}} & 0.069 \\
\hline & & 5.84 \\
\hline \multicolumn{2}{|l|}{ p-value } & 0.015 \\
\hline \multicolumn{2}{|l|}{ Learn \& share skills } & 4.77 \\
\hline \multicolumn{2}{|l|}{ p-value } & 0.028 \\
\hline Observations & 96 & 144 \\
\hline log-likelihood & -39.98 & -60.48 \\
\hline Pseudo Rsquared & 0.365 & 0.304 \\
\hline \multicolumn{3}{|c|}{$\begin{array}{l}\text { The models are estimated with a probit: marginal effects on the probability to use OS 3D printers are reported. In } \\
\text { column (1) only individuals that started to use 3D printers before } 2011 \text { are included. In column (2) only individuals } \\
\text { that started to use 3D printers from } 2011 \text { onwards are included. Wald tests based on seemingly unrelated bivariate } \\
\text { probit regression. S. e. in round brackets are clustered at the individual level. Significance level: } * * * p<0.01, * * \\
p<0.05, * p<0.1 \text {. }\end{array}$} \\
\hline
\end{tabular}




\section{Appendix}

Table A1. The adoption of proprietary or open-source 3D printers, controlling for selection

\begin{tabular}{|c|c|c|c|c|}
\hline & (1) & (2) & (3) & (4) \\
\hline VARIABLES & $\begin{array}{c}\text { 3D printing actual } \\
\text { usage }\end{array}$ & Proprietary & $\begin{array}{c}\text { 3D printing actual } \\
\text { usage }\end{array}$ & Open Source \\
\hline Bachelor & $\begin{array}{c}-0.024 \\
(0.052)\end{array}$ & $\begin{array}{c}0.192 * * \\
(0.089)\end{array}$ & $\begin{array}{c}-0.024 \\
(0.052)\end{array}$ & $\begin{array}{c}-0.155^{*} \\
(0.089)\end{array}$ \\
\hline Master or $\mathrm{PhD}$ & $\begin{array}{c}0.002 \\
(0.049)\end{array}$ & $\begin{array}{c}0.254^{* * *} \\
(0.089)\end{array}$ & $\begin{array}{c}0.002 \\
(0.049)\end{array}$ & $\begin{array}{c}-0.161^{* *} \\
(0.080)\end{array}$ \\
\hline Age & $\begin{array}{c}0.006 * * \\
(0.002)\end{array}$ & $\begin{array}{c}0.001 \\
(0.003)\end{array}$ & $\begin{array}{c}0.006 * * \\
(0.002)\end{array}$ & $\begin{array}{c}-0.002 \\
(0.003)\end{array}$ \\
\hline Male & $\begin{array}{c}0.067 \\
(0.068)\end{array}$ & $\begin{array}{c}0.008 \\
(0.120)\end{array}$ & $\begin{array}{c}0.067 \\
(0.068)\end{array}$ & $\begin{array}{c}0.045 \\
(0.098)\end{array}$ \\
\hline \multicolumn{5}{|l|}{ Country of origin } \\
\hline English -speaking & $\begin{array}{c}0.235^{* * *} \\
(0.087)\end{array}$ & - & $\begin{array}{c}0.235 * * * \\
(0.087)\end{array}$ & - \\
\hline European & $\begin{array}{l}0.121 * \\
(0.058)\end{array}$ & - & $\begin{array}{l}0.121 * \\
(0.058)\end{array}$ & - \\
\hline Work related & & $\begin{array}{c}0.245^{* * *} \\
(0.069)\end{array}$ & & $\begin{array}{c}0.062 \\
(0.063)\end{array}$ \\
\hline Maker Movement & & $\begin{array}{c}-0.113 \\
(0.083)\end{array}$ & & $\begin{array}{c}0.224 * * \\
(0.083)\end{array}$ \\
\hline \multicolumn{5}{|l|}{ Activity } \\
\hline Production & & $\begin{array}{c}0.066 \\
(0.087)\end{array}$ & & $\begin{array}{c}0.117 \\
(0.083)\end{array}$ \\
\hline Functional models/prototypes & & $\begin{array}{c}0.127 \\
(0.078)\end{array}$ & & $\begin{array}{c}0.197 * * * \\
(0.068)\end{array}$ \\
\hline Wanted Features & & & & \\
\hline New materials & & $\begin{array}{c}-0.053 \\
(0.078)\end{array}$ & & $\begin{array}{c}0.004 \\
(0.067)\end{array}$ \\
\hline Speed & & $\begin{array}{l}-0.059 \\
(0.069)\end{array}$ & & $\begin{array}{c}0.146 * * \\
(0.062)\end{array}$ \\
\hline Quality & & $\begin{array}{c}0.073 \\
(0.072)\end{array}$ & & $\begin{array}{c}-0.049 \\
(0.067)\end{array}$ \\
\hline Easiness & & $\begin{array}{l}-0.028 \\
(0.072)\end{array}$ & & $\begin{array}{c}0.239 * * * \\
(0.078)\end{array}$ \\
\hline Price Convenience & & $\begin{array}{c}0.063 \\
(0.072) \\
\end{array}$ & & $\begin{array}{c}-0.198 * * * \\
(0.071)\end{array}$ \\
\hline Rho & & $\begin{array}{c}0.501 \\
(0.598)\end{array}$ & & $\begin{array}{l}-0.5148 \\
(0.945)\end{array}$ \\
\hline Wald test of indep. equations & & 0.480 & & 0.200 \\
\hline p-value & & 0.490 & & 0.658 \\
\hline Observations & 283 & 283 & 283 & 283 \\
\hline Uncensored obs & & 240 & & 240 \\
\hline Log-likelihood & -257.1 & -257.1 & -227.5 & -227.5 \\
\hline
\end{tabular}

The models are estimated with a probit with sample selection: marginal effects are reported. The dependent variable of the selection equation in columns (1) and (3) is a dummy variable equal to 1 for individuals who actually used 3D printers and zero otherwise. The dependent variable in column (2) is a dummy variable that indicates the use of proprietary type of 3D printers. In column (4) the dependent variable indicates the use of open-source type of 3D printers. The English-speaking dummy is equal to one for users from the following countries: Australia, Canada, Hong Kong, Ireland, New Zealand, South Africa, the UK and the US. The European dummy is equal to one for all users from continental Europe (including Turkey). S. e. in round brackets are clustered at the individual level. Significance level: $* * * \mathrm{p}<0.01, * * \mathrm{p}<0.05, * \mathrm{p}<0.1$. 
Table A2. The adoption of proprietary or open-source 3D printers, only polymers

(1)

proprietary

VARIABLES

Bachelor

Master or Phd

Work related

Maker Movement

Age

Male

Activity

Production

Functional models/prototypes

Wanted Features

New Materials

Speed

Quality

Easy

Price Convenience
0.208*

(0.106)

$0.220^{* *}$

(0.112)

$0.216^{* *}$

(0.084)

$-0.214 * *$

(0.106)

0.002

$(0.005)$

0.064

(0.142)

0.126

(0.098)

0.029

(0.093)

$-0.113$

(0.097)

$-0.010$

(0.084)

0.086

$(0.084)$

$-0.038$

(0.086)

0.153*

(0.089)
(2)

open source
$-0.169 *$

(0.105)

$-0.229 * *$

(0.104)

$-0.086$

(0.076)

$0.243^{* *}$

(0.109)

$-0.002$

(0.004)

$-0.060$

(0.111)

0.063

(0.094)

$0.177 *$

(0.091)

0.093

(0.086)

0.115

(0.074)

$-0.044$

(0.075)

$0.226 * * *$

$(0.072)$

$-0.163 * *$

(0.081)

$\begin{array}{lcc}\text { Observations } & 152 & 152 \\ \text { log-likelihood } & -90.56 & -72.52 \\ \text { Pseudo Rsquared } & 0.112 & 0.199\end{array}$

Pseudo Rsquared

0.112

0.199

The models are estimated with a probit: marginal effects on the probability to adopt proprietary 3D printers and OS 3D printers are reported, respectively. Only users that exclusively print with polymers are included. S. e. in round brackets are clustered at the individual level. Significance level: ${ }^{* * *} \mathrm{p}<0.01,{ }^{* *} \mathrm{p}<0.05,{ }^{*} \mathrm{p}<0.1$. 